\title{
Autosomal recessive Klippel-Feil syndrome
}

\author{
ELIAS OLIVEIRA DA SILVA \\ From the Departamento de Biologia Geral, Secção de Genética, Universidade Federal de Pernambuco, \\ and Instituto Materno-Infantil de Pernambuco (IMIP), Recife, Brazil
}

SUMMARY An inbred kindred with 12 cases of Klippel-Feil syndrome (seven females and five males) is reported. Inheritance is undoubtedly autosomal recessive. The main characteristic of the syndrome is fusion of cervical vertebrae.

In 1912, Klippel and Feil ${ }^{1}$ reported the first clinical details and necropsy findings of a syndrome characterised by the triad short or absent neck, severe limitation of head movement, and low posterior hairline. An Egyptian mummy (from 500 BC) is the oldest subject in whom Klippel-Feil syndrome has been seen. ${ }^{2}$ Another interesting observation is the similarity between the figure of an old man depicted by the English painter William Blake (1757-1827) and the appearance of persons with Klippel-Feil syndrome. $^{3}$ The incidence of the syndrome is estimated at about 1 in 42000 births. ${ }^{4}$ Some authors have suggested that males and females are equally afflicted, ${ }^{56}$ but others have reported a higher incidence in one or the other sex. ${ }^{7}$

The main anomalies associated with this syndrome are Sprengel's deformity, spina bifida (especially of the cervical spine), deafness (especially of the sensorineural type), scoliosis or kyphoscoliosis, and pterygium colli. Many less common abnormalities are found with Klippel-Feil syndrome, involving the musculoskeletal, nervous, gastrointestinal, urogenital, cardiovascular, and respiratory systems, and oral and dermatological manifestations are also found. In some of these associations, Klippel-Feil syndrome is only part of a wider and better delineated syndrome, as in Wildervanck syndrome ${ }^{8-10}$ and in the syndrome described more recently in two unrelated females by Park et al ${ }^{11}$ (Klippel-Feil deformity, conductive deafness, and absent vagina). Klippel-Feil syndrome has also been reported in association with Rokitansky-Kuster-Hauser, ${ }^{12} 13$ Duane, ${ }^{14}$ and fetal alcohol ${ }^{15}{ }^{16}$ syndromes.

This study of an inbred kindred from the northeast of Brazil with 12 cases of Klippel-Feil syndrome clearly establishes an autosomal recessive mode of inheritance for the syndrome.

Received for publication 10 June 1981

\section{Methods}

A total of 59 members of the family, including all living affected persons (11), were clinically examined and radiological studies were performed in eight patients. The other three refused to submit to $x$-ray examination. The patients ranged in age from 9 to 59 years.

The genealogical data was collected with the cooperation of people in four generations and, in case of doubtful information, it was checked with different members of the family.

\section{Results}

The pedigree of the family with 12 cases of KlippelFeil syndrome (seven females and five males) is shown in fig 1 . The patients belonged to four separate sibships and each one had unaffected parents who were first cousins. Inheritance is undoubtedly autosomal recessive. Subject V.15, an unaffected man, married two affected sisters (his third cousins). As all seven children of the two marriages were unaffected, it is presumed that he is a homozygote.

Pictures of six patients are shown in fig 2. Subjects V.16, VI.32, VI.36, VI.39, and VI.72 had short stature (their heights were below the 3 rd centile).

The main radiological findings (fig 3 ) observed in eight patients included, besides the classical fusion of cervical vertebrae, upper thoracic vertebral fusion, Sprengel's deformity, scoliosis, and bilateral rib fusion in all cases. Two affected sibs also had lumbar fusion (one of T12-L1-L2 and the other of L1-L2) and absence of the last lumbar vertebra and a pair of ribs. Sacral malformation was found in six patients. Excretory urography, performed in five patients, showed absence of the right kidney in one of them (subject VI.37). 


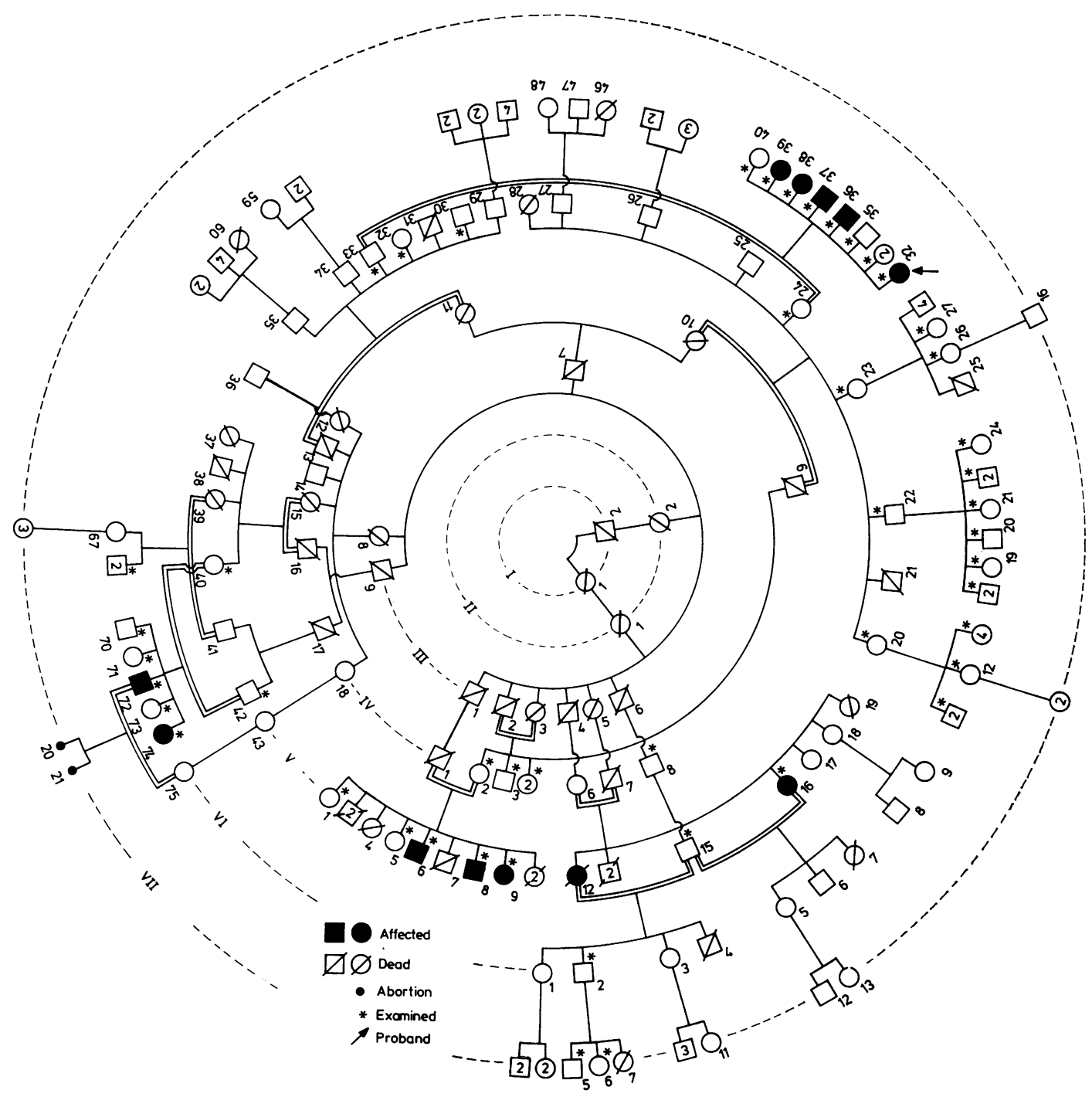

FIG 1 Pedigree of family.

\section{Discussion}

About 300 papers on Klippel-Feil syndrome have been published. Most are reports of sporadic cases with descriptions of associated abnormalities without consanguinity, suggesting that the usual cause is environmental or multifactorial.

According to Feil's classification, ${ }^{17} 18$ there are three morphological types of Klippel-Feil syndrome: (1) type I is a fusion of cervical and upper thoracic vertebrae, (2) type II is a localised fusion of one or two pairs of cervical vertebrae, and (3) type III is a combination of cervical fusion and lower thoracic or lumbar fusion. In this series, among the eight $x$-rayed patients, six have the type I syndrome (cervical and upper thoracic fusions) and two (with cervical, upper thoracic, and lumbar fusions) cannot be classified in any one of the three types. Apparently, Feil's classification needs to be expanded to include the cases with fusion of cervical, upper 


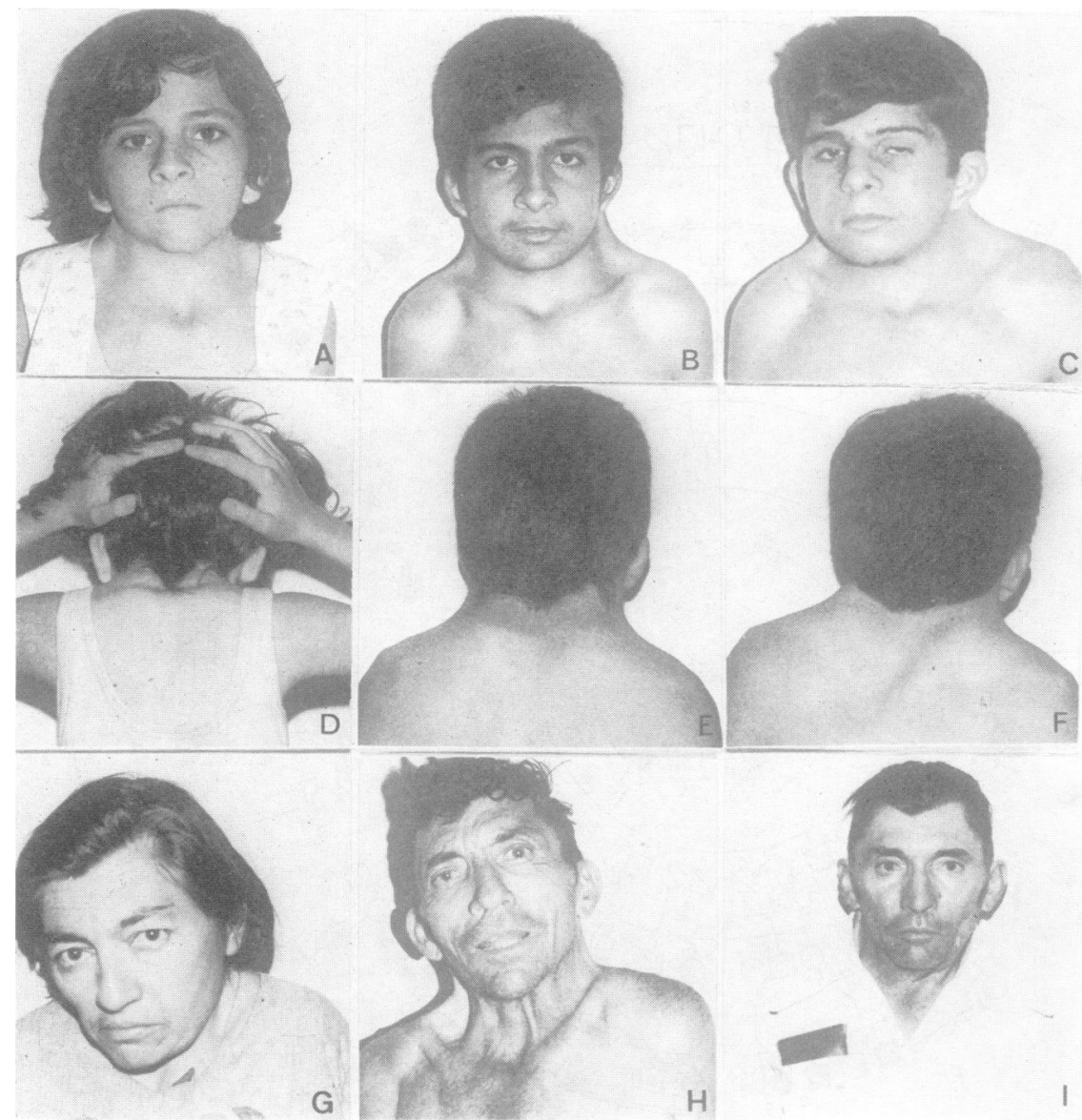

FIG 2 Six patients (sibs VI.38, VI.37, VI.36 and sibs V.9, V.8, V.6) with Klippel-Feil syndrome. A-C are anterior and $D-F$ posterior aspects of the same people. Note short neck, pterygium colli, low posterior hairline, and Sprengel's deformity in all of them.

thoracic, lower thoracic and/or lumbar vertebrae in a fourth group (type IV).

Only a few papers have described two or more cases of Klippel-Feil syndrome in the same family. An affected mother and daughter and father and daughter were reported respectively by Clemmesen ${ }^{19}$ and Lynch and Grissom. ${ }^{20}$ Although suggestive of dominant inheritance, these reports did not include adequate family histories. The cases reported by Bizarro, ${ }^{21}$ Bauman, ${ }^{22}$ and Shoul and $\mathrm{Ritvo}^{23}$ are cited in published reports as suggestive of dominant inheritance. However, Bizarro's patient probably did not have Klippel-Feil syndrome because, despite having a short webbed neck and Sprengel's deformity, he did not have cervical vertebral fusion. The last two papers, like the majority of published works, actually present just sporadic cases with negative family histories. In a large study of seven families with type II fusion, Gunderson et $a^{17}$ reported autosomal dominant inheritance in five of them.

This study with a large inbred kindred (12 cases) establishes definitely that at least one autosomal recessive form of Klippel-Feil syndromeexists, and the abnormal gene, in a homozygous state, is apparently of variable expressivity since the degree of vertebral fusion was variable. Studies suggesting an autosomal recessive mode of inheritance have been reported by some authors. Baga et al $^{24}$ described an affected brother and sister with normal parents. Gunderson et $a l^{17}$ also reported two affected sibs (a brother and sister) in one of their seven families with type II fusion. 


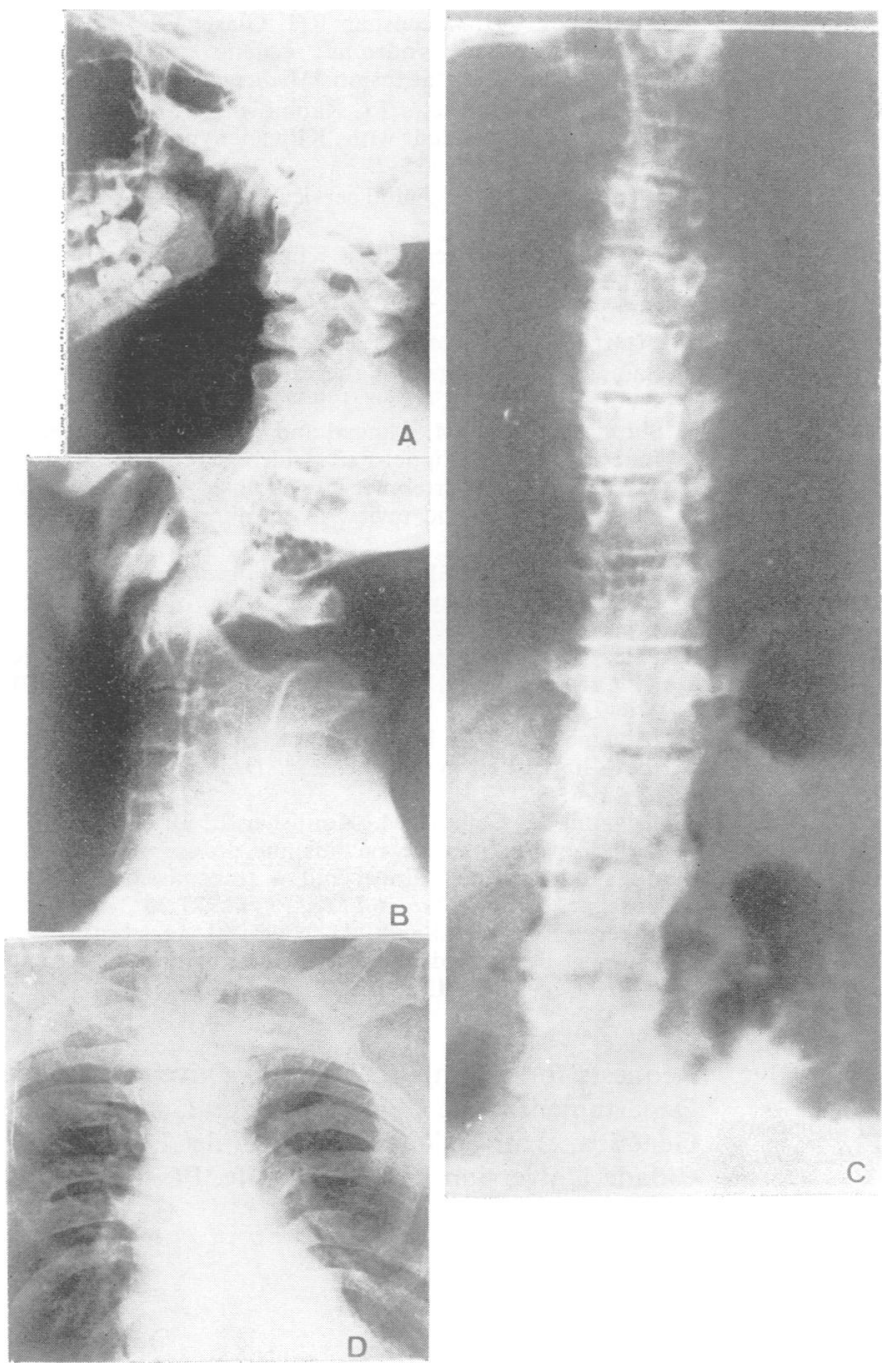

FIG. $3 X$-rays of the spine and thorax of 3 patients with Klippel-Feil syndrome. $A$. Fusion of cervical vertebrae (C4-C5). $B$ and $C$. Spine of the same patient showing fusion of cervical, thoracic, and lumbar vertebrae (C2-C5, T1-T5, and L1-L2), absence of the last lumbar vertebra, and scoliosis. D. Bilateral rib fusion.

Their parents were normal and consanguineous. Isolated cases with normal related parents have been reported by many investigators. ${ }^{25-28}$

\section{Conclusions}

(1) Klippel-Feil syndrome probably represents genetic heterogeneity, with at least two inherited forms: one autosomal dominant and the other autosomal recessive.

(2) Feil's classification with the three types of vertebral fusion does not seem to encompass all the cases of Klippel-Feil syndrome. Based on the data presented in this paper, a type IV fusion is proposed for cases with cervical, upper thoracic, lower thoracic and/or lumbar vertebral fusions.

I am very grateful to Dr José Carlos de Brito (Director, Hospital Regional Justino Luz, Picos, PI) for his generosity in the use of his facilities, and to Dr Sílvio Cavalcanti de Albuquerque for his help in the radiological studies.

\section{References}

1 Klippel M, Feil A. Un cas d'absence des vertébres cervicales avec cage thoracique remontant jusqu'à la base du crâne (cage thoracique cervicale). Nouv Iconogr Salpet $1912 ; 25: 223-50$. 
2 Ramsey J, Bliznak J. Klippel-Feil syndrome with renal agenesis and other anomalies. $A J R$ 1971;113:460-3.

3 Martin ME. A Klippel-Feil syndrome in the artistic works of William Blake. Bull Hist Med 1954;28:270-1.

4 Cooper JC. The Klippel-Feil syndrome. A rare cause of cervico-facial deformity. Br Dent J 1976;140:264-8.

5 Erskine CA. An analysis of the Klippel-Feil syndrome. Arch Pathol 1946;41:269-81.

6 Sommerfeld RM, Schweiger JW. Cleft palate associated with Klippel-Feil syndrome. Report of a case. Oral Surg 1969;27:737-9.

7 McLay K, Maran AGD. Deafness and the Klippel-Feil syndrome. J Laryngol Otol $1969 ; 83: 175-84$.

8 Wildervanck LS. Een cervico-oculo-acusticussyndroom. Ned Tijdschr Geneeskd 1960;104:2600-5.

9 Everberg G, Ratjen E, Sorensen H. Wildervanck's syndrome. Klippel-Feil's syndrome associated with deafness and retraction of the eyeball. $B r J$ Radiol 1963;36:562-7.

10 Sherk HH, Nicholson JT. Cervico-oculo-acusticus syndrome. Case report of death caused by injury to abnormal cervical spine. J Bone Joint Surg 1972;54:1776-8.

11 Park IJ, Jones HW Jr, Nager GT, Chen SCA, Hussels IE. A new syndrome in two unrelated females: Klippel-Feil deformity, conductive deafness, and absent vagina. Birth Defects 1971;7:311-7.

12 Hillemand B, Bonneau J-C, Joly J-P. Conjonction d'un syndrome de Turner, d'un syndrome de RokitanskyKüster-Hauser atypique et d'un syndrome de KlippelFeil. Ann Med Interne (Paris) 1973;124:423-8.

13 Kords H. Rokitansky-Küster-syndrom (Vaginalaplasie, rudimentarer uterus) kombiniert mit nierenaplasie, phokomelie und multiplen skelettfehlbildungen im sinne eines Klippel-Feil-syndroms. Geburtshilfe Frauenheilkd 1976;36:672-7.

14 Brik M, Athayde A. Bilateral Duane's syndrome, paroxysmal lacrimation, and Klippel-Feil anomaly. Ophthalmologica 1973;167:1-8.

15 Lowry RB. The Klippel-Feil anomalad as part of the fetal alcohol syndrome. Teratology 1977;16:53-6.

16 Neidengard L, Carter TE. Klippel-Feil malformation complex in fetal alcohol syndrome. Am J Dis Child 1978;132:929-30.
17 Gunderson $\mathrm{CH}$, Greenspan RH, Glaser GH, Lubs HA. The Klippel-Feil syndrome: genetic and clinical re. evaluation of cervical fusion. Medicine 1967;46:491-512.

18 Moore WB, Matthews TJ, Rabinowitz R. Genitourinary anomalies associated with Klippel syndrome. $J$ Bone Joint Surg 1975;57:355-7.

19 Clemmesen V. Congenital cervical synostosis. Acta Radiol 1936;17:480-90.

${ }^{20}$ Lynch HT, Grissom RL. Klippel-Feil syndrome and bicuspid aortic valve: report of a case. Nebraska Med J $1966 ; 51: 428-32$.

21 Bizarro AH. Brevicollis. Lancet 1938 ;ii:828-9.

22 Bauman GI. Absence of the cervical spine. Klippel-Fei syndrome. JAMA 1932;98:129-32.

${ }^{23}$ Shoul MI, Ritvo M. Clinical and roentgenological manifestations of the Klippel-Feil syndrome (congenital fusion of the cervical vertebrae, brevicollis). Report of eight additional cases and review of the literature. AJR 1952; 68:369-85.

24 Baga N, Chusid EL, Miller A. Pulmonary disability in the Klippel-Feil syndrome. A study of two siblings. Clin Orthop 1969;67:105-10.

${ }^{25}$ Peters JJ. Two cases of Klippel-Feil syndrome associated with severe mental subnormality. Radiography $1962 ; 28$ : 316-9.

26 Miyamoto C, Ishu H, Hamamoto Y. An autopsy case of the Klippel-Feil syndrome. Bull Osaka Med Sch 1971; 17:11-6.

27 Rayanal L, Collard M, Koulisher L, Brasseur P. Description d'une forme rachidienne diffuse et thoracique du syndrome de Klippel-Feil à transmission récessive possible. J Belge Rhumatol Med Phys 1973;28:377-85.

28 Juberg RC, Gershanik JJ. Cervical vertebral fusion (Klippel-Feil) syndrome with consanguineous parents. J Med Genet 1976;13:246-9.

Requests for reprints to Dr Elias Oliveira da Silva, Departamento de Biologia Geral, Secção de Genética, Universidade Federal de Pernambuco, Cidade Universitária, 50000 Recife, PE, Brazil. 